DOI: https://doi.org/10.3126/njdrs.v16i0.31530

\title{
Prospect of Good Governance and Human Development
}

\author{
Deepak Chaudhary \\ PhD Scholar, Central Department of Rural Development \\ Kirtipur, Kathmandu \\ Email for correspondence: dipak10@gmail.com
}

\begin{abstract}
The governance now became a buzzword in political economy. It contributes to accelerating the overall development including human development and its role in making effective delivery of social and public services are crucial. This paper analyzes the relationship between governance and human development based on published data, document and theories. The concept of governance and human development emerged after 1980. The proper function of governance in terms of political, economic and administrative can create sound development. Rule of Law, participation, public accountability and responsiveness, transparency, equity and inclusion, efficiency, and decentralization are a key institutional framework for democratic or good governance. These principles are structured to performing well for the assigned goals and objectives, transparent decisions, focusing on the organization's purpose and outcomes, capacity building, and managing and mitigating risks factors. If there is enough authority, capacity, economic resource, and good governance, human development can easily be achieved. Therefore, the linkage between governance and human development is inevitable.
\end{abstract}

Key words: Capacity building, good governance, human development, political economy

\section{Background}

Over time, 'development' is understood as different meanings. Following the industrialization in the mid-18th century, the modern development process was considered to have begun. Following the World War-II, development was introduced in planning and systematic way through institutions to set up the new political-economic structure and development focused on economic growth particularly. In the concept of economic growth of development, the human was considered as labors or means; it was not considered as a sole beneficiary. After 1980, resistances emerged in many parts of the world, as it could not go below (Escobar, 1995) and debt-problem emerged as a worldwide's problem. Many countries failed to achieve the goals of development due to the lack of political willingness and good governance. Good governance is considered to be enhancing for sound development. The concept of human development emerged after 1990 as a part of alternative development and human capital and its importance was realized. The health, knowledge, and skills as a part of human development attracted to the many. The human capabilities and freedom became a major part of human development.

Nepal's experience regarding the development is not more different from other developing country' experiences. After 1950, Nepal introduced the modern concept of development in terms of Nepalese Journal of Development and Rural Studies, Volume 16, 2019 
GNI (Gross National Index) or industrialization through five-year plans. However, development could not make a big leap; underdevelopment remains for longs. Pandey (1999, p. 6) mentions that the word 'bikas' sells in the country -as a dream, as an occupation; and as a weapon to beat one's political opponents with, but the subject has not been internalized as a mission. After 1990, Nepal also adopted the human development approach focusing on people and their living standards along with economic growth. In 1998, Nepal published its first human development report. Then after, five themes of HDRs have been published in different subjects. However, Nepal faces poor human development progress. Nepal's ranking in the human development index is 145, which is lower in South Asia (UNDP, 2014). Therefore, the role of good governance in order to achieve sound human development is crucial.

\section{Governence and Human Development}

Governance. Mainly, the governance relates to the institutions (i.e. its mechanism, processes, and functions) either traditional or modern by which authority is exercised; where citizens and groups communicative and exercise their legal rights. Hence, the success of governance in terms of planning, policies, strategy, and implementation determines the success of the development. Human development is a new approach that focuses on people primarily. To promote and sustain human development, the system of governance's role is vital. Presently, developing countries including Nepal have been facing problem and challenge of implementing human development in the absence of good governance.

As of UNDP (1990) governance as the exercise of political, economic and administrative authority in the management of the country's affairs at all levels. Therefore, it includes the mechanism, process, relationship and institutions through which people and group communicate and interact to get developmental goals. For, the functioning of the political economy, rule of law is essential; the state, civil society and private-sectors/markets are three component of the political economy. Haq (1995) focuses on human governance that enables the state, civil society and the private sector to build capacities, which will meet the basic needs of all. Therefore, the relationship among state, government, and civil society are important and the role of governance is crucial. In this circumstance, the function of these economic, political and administrative governances in institutions is important. The economic governance includes decision making in resources, budgetary part and the easy access on market for people that ensure the economic activity. The political governance comprises of judicial, executive and legislative in a broader sense (Mudacumura, 2014). It includes elect-representatives, leadership, decision making in the planning of the development. Likewise, administrative governance represents the implementation body that delivers social and public services. The public delivery services may be effective if there is good governance. Apart from, the civic society's role in check and balance on state and market's monopoly is important. Democratic governance ensures participation, inclusion, equity, responsiveness, and transparency. Therefore, the democratic based institution is considered as a support means for good governance largely. The genesis of governance comes from a democratic and neo-liberal concept. 


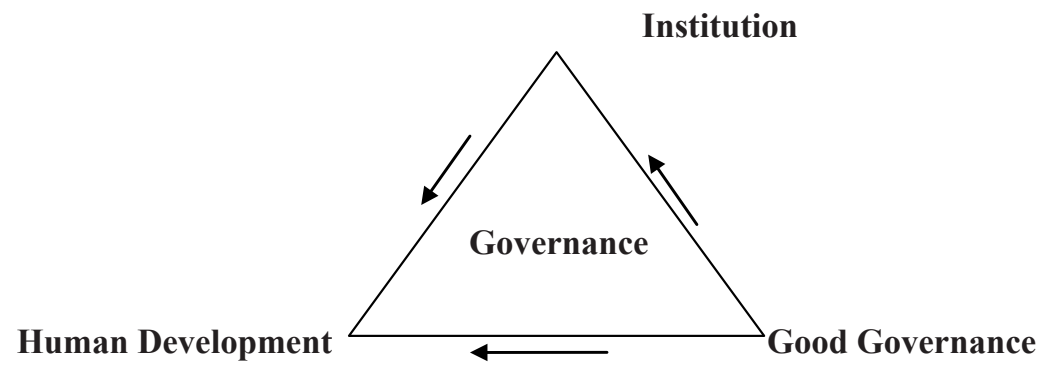

\section{Figure1. Relationship between Human Development and Good Governance}

Therefore, development and governance are interrelated; good governance can only assure and sustain human development (UNDP, 2009). Accountability, transparency, inclusiveness, and responsiveness are key parts of good governance which are crucial for sound human development.

Human development. The concept of human development introduced after the publication of the Human Development Report in 1990 prepared by UN (UNDP, 1990). People have been a central part of human development. Income, education, and health are considered key elements of human development and these are essential for enhancing human abilities and making people capable of choices. Additional choices include freedom, guaranteed human rights and personal self-respect. The expansion of freedom is central to development (Sen, 2000). Equity, sustainability, production, and empowerment are four essential components in the human development paradigm (Haq, 1995).

According to the HDR 1990-, "Human development is a process of enlarging people's choices. The most critical of these wide-ranging choices are to live a long and healthy life, to be educated and to have access to resources needed for a decent standard of living." (p. 11). The life expectancy for longevity, literacy rate and school attainment for knowledge and income for decent living standards are fixed as indicators in order to measure these elements. "Human development has two sides: the formation of human capabilities - such as improved health, knowledge, and skills- and the use people make of their acquired capabilities. If the scales of human development do not finely balance the two sides, considerable human frustration may result." (HDR, 1990, p. 12) Human development ultimately strengthens human capital, which is considered to be essential for economic development.

Global human development. UNDP, the body of the UN, has been publishing the Human Development Report (HDR) yearly in different themes. The first human development report exposed enlarging people's choices. Mobilization of maximum resources for social services was prioritized by 1991 HDR. HD 1993 focused on inclusive and collective action through decentralization strengthens civil society and people's participation. Similarly, HDR 1995 emphasized gender inequality. Poverty was given a priority by HDR 1997. Poverty has two dimensions- in the form of income and in deprivation form. HD 1999 paved the way of the impact of globalization. Human right and human freedom were discussed in HD 2001R. Meanwhile, HDR 2002 focused on political implication and democratic governance to safeguard freedom and dignity and empower people. Likewise, HDR 2003 explored the Millennium Development Goals (MDGs) adopted by 189 countries at the UN in 2000. The MDGs are a global compact among nations to end human poverty. The theme of cultural liberty to choosing one's identity without being excluded from other choices in building a full life emphasizes 
multi-cultural policy was focused in HDR 2004. Climate change was highlighted in HDR 2007/8. HDR 2016 emphasizes human development for everyone. In 2010, the Inequality-adjusted HDI (IHDI) was first introduced; The IHDI is the HDI adjusted for inequalities in the distribution of achievements in each of the three dimensions of the HDI (health, education, and income). In this way, various themes as per necessitate have been focused by HDRs.

Human development index. Human Development Index (HDI) is a summary measure of average achievement in key dimensions of human development. The HDI is the geometric mean of normalized indices for each of the three dimensions. According to HDR 2018, the health dimension is assessed by life expectancy at birth; the education dimension is measured by mean of years of schooling for adults aged 25 years and more and expected years of schooling for children of school entering the age. The standard of living dimension is measured by gross national income per capita. The indicators of the three dimensions are calibrated and an HDI score set between zero and one. Four human development categories or quartile such as very high, high, medium and low are classified. Very high HDI ranks above 75, 51-75 represents high, and 26-50 represents the medium group and below it is classified under bottom quartile. Figure 2 shows the principle of human development indexes:

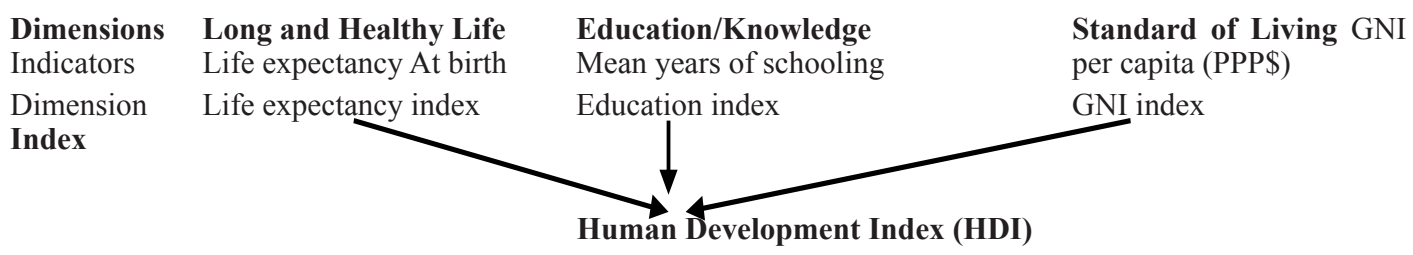

Figure 2. The Principles of Human Development Index Composition (http://hdr.undp.org/en/content/human-development-index-hdi)

\section{Objectives}

- To assess the relationship between governance and human development.

- To analyzes role of governance in the human development pragmatic way.

\section{Methods and Materials}

This work is based on analysis and literature reviews and secondary data including published Human Development Reports (HDRs). The study is exploratory and analytical in nature because it intends to explore the focus of the trends of human development worldwide and Nepal. Besides, the theories regarding development and governance are reviewed.

\section{Discussions: Nepal Human Development}

The first Nepal Human Development report was published in 1998 and then, five themes of HDRs have been published in different contemporary issues till now. HDR 1998 explored public domain and planning in the country. Poverty reduction and governance were dealt with by HDR 2001. HDR 2002 focused on empowerment and poverty reduction. Likewise, HDR 2009 explored state transformation and human development. Similarly, HDR 2014 focused on beyond geography, unlocking human potential. In this way, various themes have been dealt with by human development reports. Tenth plan (2002-2007) of Nepal has also included the human development approach, which 
announced inclusion, empowerment, and affirmative action's to bring poor, women and disadvantaged to development mainstream.

\section{Trends of Nepal Human Development}

As of Human Development Indices and Indicators: 2018 Statistical Update, Nepal's HDI value for 2017 is 0.574 , which put the country in the medium human development category. Nepal's ranking is at 149 out of 189 countries. Table-1 reveals that life expectancy is higher in comparison with the average of South Asia, however, mean years of schooling is found below South Asia. Similarly, Nepal's GNI per capita is much lower in South Asia. Sri Lanka represents the highest HDI value (0.77) -positioning 76 out of 189 countries.

Table 1. HDI and Indicators for Selected Countries and Groups, 2017

\begin{tabular}{|c|c|c|c|c|c|c|}
\hline Countries & $\begin{array}{l}\text { HD } \\
\text { Value }\end{array}$ & $\begin{array}{l}\text { HDI } \\
\text { Rank }\end{array}$ & $\begin{array}{l}\text { Life Expectancy at } \\
\text { birth }\end{array}$ & $\begin{array}{l}\text { Expected years } \\
\text { of schooling }\end{array}$ & $\begin{array}{l}\text { Mean years } \\
\text { of schooling }\end{array}$ & $\begin{array}{l}\text { GNI Per capita } \\
(2011 p p p \$)\end{array}$ \\
\hline Nepal & 0.574 & 149 & 70.6 & 12.2 & 4.9 & 2271 \\
\hline Afghanistan & 0.498 & 168 & 64 & 10.4 & 3.8 & 1824 \\
\hline Sri Lanka & 0.77 & 76 & 75.5 & 13.9 & 10.9 & 11326 \\
\hline South Asia & 0.638 & & 69.3 & 11.9 & 6.4 & 6473 \\
\hline Medium HDI & 0.645 & & 69.1 & 12 & 6.7 & 6849 \\
\hline
\end{tabular}

(UNDP, 2018)

Nevertheless, Nepal has been improving its HDI over the decades. In 1990, Nepal was counted in bottom quartile; mean years of schooling and expected years of schooling was only 2 and 7.5 (refer Table-2). Now it has been near doubled over two decades. Similarly, life expectancy at birth has steadily been increased from 54.3 in 1990 to 70.6 years in 2017. Likewise, GNI per capita has also been doubled over the decades. Overall HDI value is improving as it was 0.378 , which represents low quartile. Table-2 reviews Nepal's progress in HDI indicators:

Table 2. Nepal's HDI Trends based on Consistent Time Series

\begin{tabular}{lccccc}
\hline Years & $\begin{array}{l}\text { Life expectancy at } \\
\text { birth }\end{array}$ & $\begin{array}{l}\text { Expected years of } \\
\text { schooling }\end{array}$ & $\begin{array}{l}\text { Mean years of } \\
\text { schooling }\end{array}$ & $\begin{array}{c}\text { GNI Per capita } \\
\text { (2011ppp\$) }\end{array}$ & $\begin{array}{l}\text { HDI } \\
\text { value }\end{array}$ \\
1990 & 54.3 & 7.5 & 2 & 1168 & 0.378 \\
1995 & 58.5 & 8.1 & 2.2 & 1322 & 0.41 \\
2000 & 62.4 & 9 & 2.4 & 1526 & 0.446 \\
2005 & 65.5 & 9.6 & 2.8 & 1689 & 0.475 \\
2010 & 67.9 & 12 & 3.3 & 2001 & 0.529 \\
2015 & 69.9 & 12.2 & 4.7 & 2353 & 0.566 \\
2016 & 70.3 & 12.2 & 4.9 & 2334 & 0.569 \\
2017 & 70.6 & 12.2 & 4.9 & 2471 & 0.574 \\
\hline
\end{tabular}

(UNDP, 2018)

Nepal Human Development Report (HDR) 1998 first published regarding the inequalities by caste/ethnicity. Further, HDR 2014 derived human development index by caste/ethnicity based on the 2011 census. As of HDR 2014 report, the Brahmans/ Chhetris and Newar rank at the top with an HDI. Similarly, Dalits including both hill and Tarai have the highest poverty headcount rate followed by Janajati and Muslim.

Nepalese Journal of Development and Rural Studies, Volume 16, 2019 
Table 3. HDR based on Caste/Ethnicity

\begin{tabular}{lcc}
\hline Caste/Ethnic Group & Poverty Headcount Rate & Percent of Poor \\
\hline Hill Brahman & 10.3 & 5.2 \\
Hill Chhetri & 23.4 & 16.6 \\
Tarai Brahman & 18.6 & 0.4 \\
Tarai middle caste & 28.7 & 17.6 \\
Hill Dalit & 43.6 & 15.2 \\
Tarai Dalit & 38.2 & 6.9 \\
Newar & 10.3 & 2.5 \\
Hill Janajati & 28.3 & 24.4 \\
Tarai Janajati & 25.9 & 7.3 \\
Muslim & 20.2 & 3.5 \\
Other & 12.3 & 0.5 \\
Nepal & 25.2 & 100 \\
\hline
\end{tabular}

(NHDR, 2014)

\section{Structures of Good Governance}

According to the World Bank (1992), "Governance is defined as the manner in which power is exercised in the management of a country's economic and social resources for development". UNDP 2009 acknowledges participation, transparency, responsiveness, consensus, orientation, equity, effectiveness and efficiency, accountability and strategic vision as a core characteristic of governance. Mudacumura (2014) mentions that good governance or democratic governance is a practice, the implementation of which is critical in allowing both developed and developing countries to be in the driver seat as they control their political, economic and social development effectively (p. 2). Good governance is becoming more and more commonplace as a key element of development. Good governance is central to creating and sustaining an environment, which fosters strong and equitable development (World Bank, 1992, p. 47).

The Governance practice supports to build capable, efficient, inclusive, responsiveness and accountable institutions and it enhances sound human development. Freedom, participation, public accountability and responsiveness, transparency, equity and inclusion, efficiency, and decentralization are a key institutional framework for good governance. Governance is the act of governing. It consists of a part of decision-making or leadership processes. Governance has also been defined to refer to structures and processes that are designed to ensure accountability, transparency, responsiveness, rule of law, stability, equity and inclusiveness, empowerment, and broad-based participation. In a broad sense, governance is about the culture and institutional environment in which citizens and stakeholders interact among themselves and participate in public affairs. It is more than the organs of the government that are presented below:

State, governance and civil society. The role of civil society in promoting good governance is vital for healthy development. Therefore, balance among government, citizens and civil society is essential for human development.

Democratic or good governance. In 1989, the World Bank used the term "governance" to describe the need for institutional reform and efficient public sector in Africa (Keping, 2018) and then, good governance term has frequently been used. Good governance includes participatory, transparent, 
accountable, effective and equitable and promotes the rule of law. Now a day's good governance is the basic requirement for foreign help or aids. Good governance is considered as last resort whereas governance reform is a journey for reaching the desired destination.

The principle of good governance. According to UNDP (1997), there are eight basic principles of governance which are summarized below:

Participation/empowerment. Participation is the most essential things for good governance. As far as possible, the most vulnerable groups in society should be included in decision-making. Government alone cannot end corruption, ensures accountability, impartiality, competent and able administration. Therefore, there should be active participation of the people, the civil society and nongovernmental organizations to maintain good governance. It is one of the challenges of governance in Nepal. Participation of Nepalese citizens in the state affairs directly or through legitimate institutions or representatives is important for good governance in Nepal.

Rule of law. Good governance requires fair judicial frameworks for maintaining the law that ensures the right of stakeholders. Good governance cannot be achieved if there are weak, incompetent and corrupted judiciary and police force.

Transparency. Transparency is the most essential things for good governance. Good governance can be promoted only where decisions are made and implemented according to rules and regulations in a transparent way and public information is available easily.

Responsiveness. Responsiveness is the most essential things for good governance; it means being responsiveness to the needs and expectations of the people. It is the duty of the responsible officials to serve and deliver services to the people within stipulated time-frame.

Consensus. Good governance requires consultation to understand the different interests of stakeholders in order to reach a broad consensus. It makes development as sustainable and localstakeholders take its ownership's feeling.

Effectiveness and efficiency. Good governance should ensure the effective and efficient use of available resources in the most transparent and accountable ways. This will ensure good services for public delivery.

Accountability. Good governance requires accountability on the part of every institution: government or private towards the people going to be affected by its decisions or actions.

Issues and Challenges of Good Governance

Political challenge. Political instability, frequent change in government, weak peace and security, strike, agitation, violence and so on are the key challenges in political governance.

Economic challenge. Many developing countries have been facing a shortage of human/ cultural capital. Presently, Nepal is facing a scarcity of skilled manpower because most of them are going to abroad.

Legal and constitutional related challenge. The lack of practicing law or rules, no proper punishment for corruption, political interference in the judiciary, and delay in making rules are the challenges in the wake of good governance.

Administrative related challenge. Lack of trained staff and professionals, poor technology, and corruption are the key challenges in administrative governance. 


\section{Conclusion}

Human development is indeed important as it makes people capable and its positive role in alleviating poverty is not hidden. Good governance can play a vital role in this regard. The Kerala state of India is a worthy example in the world who achieved sound human development (education $\&$ health sector) through good governance despite low economic development and it strengthen social integrity. Therefore, the relationship between governance and human development is interrelated; good governance can make an effective role in the implementation of human development and the improvement of human development can also contribute to good governance.

\section{References}

Bista, D. B. (1991). Fatalism and development. Hyderabad: Orient Longman Private Limited.

Bourdieu, P. (1986). The forms of capital (J. Richardson, Ed.) New York: Greenwood.

CBS (2012). National population and housing census 2011(Village development committee/ municipality of Sunsari \& Morang Districts). Kathmandu: National Planning Commission.

Escobar, A. (1995). Encountering development: The making and unmaking of the Third World. New Jersey: Princeton University Press.

Haq, M. U. (1995). Reflections on human development. New York: Oxford University Press.

Keping, Y. (2018, 03). Governance and good governance: A new framework for political analysis. Fudan Journal of the Humanities and Social Sciences, 11(1), 1-8.

Mudacumura, G. M. (2014). Challenges to democratic governance in developing countries (G. M. Mudacumura, Ed.) Switzerland: Springer International Publishing.

Neumayer, E. (2010). Human development and sustainability. New York: UNDP.

NPHC (National Population Housing Census). (2011). National report. Vol-1. Central Bureau of Statistics (CBS). Kathmandu: Government of Nepal.

Pandey, D. R. (1999). Nepal's failed development reflections on the mission and the maladies (10th ed.). Kathmandu: Nepal South Asia Center.

Sen, A. (2000). Development as freedom. New Delhi: Oxford University Press.

Sisodia, Y. S. (2013). Democratic governance and human development: Stocktaking and future strategies (Y. S. Sisodia, Ed.). Jaipur: Rawat Publication.

Subedi, S. L. (2014). Fiscal decentralization in Nepal. New Delhi: Adarsh Enterprises .

The World Bank. (1992). Governance and development. Washington D.C: The World Bank.

Transparency International (TI). (2017). Corruption, index perception. Berlin: Author.

Todaro, M. P., \& Smith, S. C. (2012). Economic development (10th ed.). Noida: Pearson Education Limited.

UNDP (1990). Human development report. New York: Oxford University Press.

UNDP (1998). Nepal human development report. Kathmandu: Nepal South Asia Center.

UNDP (1998-2014). Nepal human development report. Kathmandu: National Planning Commission.

UNDP (2018). Human development indices and indicators: 2018 statistical update. New York:

United Nations Development Programme. 